\title{
LA INMUNORREACTIVIDAD A CALBINDINA EN CÉLULAS DE PURKINJE DEL CEREBELO DE RATONES NO ES AFECTADA POR LA INFECCIÓN CON VIRUS DE LA RABIA
}

Julián Ricardo Naizaque G. ${ }^{1}$ Orlando Torres-Fernández. ${ }^{2}$

\section{RESUMEN}

Introducción: La calbindina $(\mathrm{CB})$ es una proteína reguladora del calcio intracelular y la célula de Purkinje del cerebelo es la neurona con más alta concentración de CB. Se ha demostrado pérdida de inmunorreactividad a $\mathrm{CB}$ en diferentes áreas del sistema nervioso en ratones inoculados con virus de la rabia, pero faltaba estudiar este fenómeno en el cerebelo. Objetivo: Determinar el efecto de la inoculación con virus de la rabia sobre la expresión de CB en células de Purkinje del cerebelo de ratones. Metodología: Se inocularon ratones con el virus por vía intramuscular. Se sacrificaron los animales cuando alcanzaron la fase avanzada de la enfermedad y se fijaron mediante perfusión intracardiaca con paraformaldehído al $4 \%$. Se les extrajo el cerebelo y se hicieron cortes sagitales de 50 micrómetros de espesor en un vibrátomo. Estos se procesaron mediante inmunohistoquímica para revelar la presencia de CB o de antígenos del virus de la rabia. El mismo procedimiento se realizó con animales no infectados (controles). Resultados: Las células de Purkinje fueron masivamente infectadas con el virus de la rabia. En las imágenes panorámicas observadas en el microscopio se comprobó que sólo estas células fueron inmunorreactivas a CB. No se hallaron diferencias significativas en la inmunorreactividad a CB, evaluada por densitometría óptica, entre los animales infectados y los controles. Conclusión: La expresión de CB en las células de Purkinje del cerebelo parece no afectarse por la infección con rabia, a diferencia de lo que se ha demostrado en otras áreas del sistema nervioso del ratón.

Palabras clave: rabia, calbindina, cerebelo, células de Purkinje, proteínas de unión a calcio.

\footnotetext{
${ }^{1}$ Biólogo, Estudiante de Maestría en Neurociencias. Laboratorio de Microscopía, Grupo de Morfología Celular, Instituto Nacional de Salud (INS). Bogotá, Colombia. Correo: jrnaizaqueg@unal.edu.co

${ }^{2}$ Biólogo, Magíster en Morfología, Doctor en Ciencias Biomédicas. Laboratorio de Microscopía, Grupo de Morfología Celular, Instituto Nacional de Salud (INS). Bogotá, Colombia. Correo: otorresf@ins.gov.co
} 


\section{IMMUNOREACTIVITY TO CALBINDIN IN PURKINJE CELLS IN THE CEREBELLUM OF MICE IS NOT AFFECTED BY RABIES VIRUS INFECTION}

\section{ABSTRACT}

Introduction: Calbindin $(\mathrm{CB})$ is a regulatory protein of intracellular calcium, and the cerebellar Purkinje cell is the neuron with the highest concentration of $C B$. Loss of $C B$ immunoreactivity has been demonstrated in different areas of the nervous system in rabies virus-infected mice, but the study of this phenomena in the cerebellum lacked. Objective: To determine the effect of inoculation with rabies virus on the expression of CB in Purkinje cells of the cerebellum of mice. Methodology: Mice were intramuscularly inoculated with rabies virus. Animals were sacrificed when they

\section{INTRODUCCIÓN}

La rabia es una zoonosis originada por un virus neurotrópico que afecta a mamíferos domésticos y salvajes, y se propaga a los humanos principalmente por mordedura con saliva infectada. Causa unas 60.000 muertes anuales más que cualquier otra enfermedad zoonótica, principalmente en Asia y África, en poblaciones pobres que no disponen de vacunación adecuada ni tratamiento profiláctico $(1,2)$. En Latinoamérica y el Caribe han disminuido notablemente los casos de rabia gracias a los programas de erradicación de la rabia canina. No obstante, la falta de atención médica oportuna en algunas regiones y la transmisión originada por la fauna silvestre, mantienen a esta enfermedad como un problema de salud pública en América Latina (3), incluyendo a Colombia (4). reached an advanced stage of the disease and then they were fixed by intracardiac perfusion with $4 \%$ paraformaldehyde. Cerebellums were extracted and sagittal sections 50 microns thick were obtained in a vibratome. These were processed by immunohistochemistry to reveal the presence of $C B$ protein or rabies virus antigens. The same procedure was performed with uninfected animals (controls). Results: Purkinje cells were massively infected with rabies virus. In the microscopic panoramic images observed was found that only these cells are immunoreactive to $\mathrm{CB}$. No significant difference in $\mathrm{CB}$ immunoreactivity evaluated by optical densitometry was found between infected animals and controls. Conclusion: The expression of CB in Purkinje cells of the cerebellum appears not to be affected by infection with rabies unlike what has been shown in other areas of the mouse nervous system.

Key words: rabies, calbindin, cerebellum, Purkinje cells, calcium binding proteins.

Dentro de las manifestaciones clínicas de la rabia están: hidrofobia e hiperexcitación, alucinaciones, debilidad progresiva de las extremidades hasta la parálisis, coma y finalmente la muerte del paciente. Cuando aparecen los primeros síntomas neurológicos, el desenlace es inevitablemente fatal, por esta razón es una de las enfermedades con más alta tasa de mortalidad $(1,5,6)$. No obstante, los hallazgos histopatológicos en el sistema nervioso central (SNC) de los animales infectados no explican la severidad del cuadro clínico de la rabia y su letalidad $(6,7)$. En el examen neurohistológico post mortem sólo se detectan alteraciones mínimas del tejido nervioso y no se observan signos de muerte celular, tales como necrosis o apoptosis en la infección natural (7-9). Por esta razón, se ha sugerido que la fisiopatología de la rabia se fundamenta más en disfunción neuronal que en daño morfológico tisular (10). 
Por lo tanto, se requiere más investigación para entender los mecanismos básicos involucrados en esta enfermedad, por ejemplo, mediante el uso de métodos que aporten información más allá de la que ofrece la histopatología convencional (11). Una alternativa para el estudio histoquímico de patologías que afectan al sistema nervioso es el uso de marcadores de poblaciones neuronales, tales como las proteínas de unión a calcio (CaBP, por sus siglas en inglés), conocidas además por ser reguladores metabólicos del calcio intracelular $(11,12)$. La inmunorreactividad de estas proteínas ha sido evaluada en el tejido nervioso de enfermedades neurológicas tales como el Alzheimer (13-15), el Parkinson, la corea de Huntington (15) y la esquizofrenia (16), así como en casos de encefalitis por sida (17).

Dentro de las CaBP, la calbindina (CB) se destaca por su interacción con proteínas involucradas en cascadas de señalización que usan el calcio como segundo mensajero $(18,19)$. La $\mathrm{CB}$ es comúnmente encontrada en neuronas gabaérgicas del SNC $(11,12,20,21)$ y hay evidencia experimental que sugiere efecto de la rabia sobre el sistema de neurotransmisión gabaérgica $(22,23)$. En estudios previos hemos reportado disminución en la inmunorreactividad a CB, en diferentes áreas del sistema nervioso de ratón, como respuesta a la infección con el virus de la rabia $(11,21,24,25)$.

Una de las partes del sistema nervioso en la que faltaba evaluar el efecto de la infección sobre la expresión de CB era el cerebelo, estructura importante dentro del sistema motor (el más afectado por la rabia) y cuyas células más representativas, las células de Purkinje, son generalmente infectadas por el virus. Esto se evidencia porque en ellas se forman una gran cantidad de cuerpos de Negri (rasgo patognomónico de la infección por rabia), lo que las hace una de las células preferidas para el diagnóstico histopatológico de la rabia $(6,7)$. Además, las células de Purkinje son las neuronas con mayor concentración de $\mathrm{CB}$ en todo el sistema nervioso (26). Por lo tanto, el objetivo de este estudio fue evaluar el efecto de la infección con virus de la rabia sobre la inmunorreactividad a CB en las células de Purkinje del cerebelo de ratones.

\section{MATERIALES Y MÉTODOS}

\section{Manejo de los animales e inoculación del virus de la rabia}

Se utilizaron hembras de ratones ICR-CD1 (Institute of Cancer Research - Línea CD1), de 4 semanas de edad, confinadas en el bioterio del Instituto Nacional de Salud (INS) en condiciones de temperatura y humedad controladas, y acceso libre a agua y alimento. Se utilizó virus de la cepa CVS (Challenge Virus Standard) a partir de una alícuota suministrada por el Laboratorio de Virología del INS. Para reproducir el virus se siguió el procedimiento reportado por Koprowski (27), que consiste en la obtención de diluciones seriadas a partir de la maceración de cerebros de ratones lactantes previamente infectados con el virus por vía intracerebral y su posterior titulación (11).

Para llevar a cabo el estudio aquí propuesto, se inocularon 7 ratones por vía intramuscular en las extremidades posteriores con una cantidad de $0,03 \mathrm{~mL}$ de dilución $1 / 10$ equivalente a $10^{9}$ DL50. Cada animal infectado tuvo su respectivo control que correspondía a un animal inoculado con solución vehículo, (solución diluyente sin el virus). Para todos los procedimientos se siguieron las normas éticas y legales requeridas para la investigación con animales de laboratorio en Colombia (Ley 84 de 1989 y Resolución No. 8430 de 1993 del Ministerio de Salud) y con aprobación otorgada por el Comité de Ética del INS.

\section{Extracción, post-fijación y preparación del cerebelo}

Los ratones inoculados con el virus y sus controles fueron sacrificados cuando los infectados 
Julián Ricardo Naizaque G. y Orlando Torres-Fernández.

alcanzaron la fase avanzada de la enfermedad, los 6 días a partir de la inoculación (caracterizada por presentar pelo erizado, superficie corporal muy fría, parálisis de las extremidades inferiores y pérdida de peso acentuada). Para extraer los encéfalos se anestesiaron los animales mediante una inyección de 0,2 $\mathrm{mL}$ de hidrato de cloral al $30 \%$ por vía intraperitoneal (350mg/ $\mathrm{Kg}$ ). A continuación, se realizó la fijación por perfusión intracardiaca, inicialmente con 50 $\mathrm{mL}$ de solución amortiguadora de fosfatos salina (PBS) a pH 7,3 e inmediatamente después con $100 \mathrm{~mL}$ de paraformaldehído (PFA) al $4 \%$. Finalmente, se extrajeron los encéfalos completos, se transfirieron a PFA al $4 \%$ y se conservaron a $4^{\circ} \mathrm{C}$ hasta su procesamiento para inmunohistoquímica, una o dos semanas después.

Se separaron los dos hemisferios con una cuchilla a lo largo de la cisura longitudinal. Luego se desprendió el cerebelo y se colocó en un vibrátomo (Vibratome $® 1000$ Plus) en el que se realizaron cortes seriados, de $50 \mu \mathrm{m}$ de espesor, en plano sagital en dirección lateral a medial. Los cortes se recogieron con un pincel y se trasladaron a recipientes pequeños de vidrio (semejantes a cajas de Petri) dentro de los cuales se llevaron a cabo las reacciones inmunohistoquímicas. Los cortes se mantuvieron en flotación y agitación constante así como a temperatura ambiente $\left(20^{\circ} \mathrm{C}\right)$ durante todo el procedimiento.

\section{Inmunohistoquímica}

Cada secuencia de dos cortes seriados se destinó alternativamente para la inmunodetección de CB y de antígenos virales de rabia siguiendo el protocolo inmunohistoquímico básico publicado anteriormente $(11,28)$, el cual se resume así: los cortes se lavaron tres veces con PBS a pH 7,3 (posteriores lavados se hicieron también con la misma solución); se trataron con cloruro de amonio 0,05M durante 30 minutos para limpiar los aldehídos; se lavaron y se incubaron en peróxido de hidrógeno al $3 \%$ durante 30 minutos para bloquear la peroxidasa endógena; de nuevo se lavaron y se procedió a incubarlos en una solución para bloquear sitios inespecíficos y permeabilizar las membranas; esta solución se componía de suero normal al 3\%, albúmina de suero bovino al 3\% y tritón al 10\% durante 1 hora. A continuación se retiró la solución anterior, y sin lavar, los cortes se incubaron toda la noche en el anticuerpo primario: anti-CB (Sigma S9848 clon CB-955) en dilución 1:2500 o en anticuerpo elaborado contra el virus de la rabia en dilución 1:1000 (antisuero elaborado en conejo) (28).

Al día siguiente los cortes destinados a la inmunorreacción para $\mathrm{CB}$ se lavaron y se incubaron en anticuerpo secundario biotinilado (anti-raton IgG Sigma, 1:400), durante 2 horas y los cortes para inmunotinción de rabia se incubaron en anticuerpo biotinilado (anti-conejo IgG Sima, 1:600) durante 1 hora. Luego, todos los cortes se trataron con solución ABC (complejo avidina-biotina-peroxidasa) (Vectastain) por 2 horas. Por último, el revelado se llevó a cabo con el cromógeno diaminobenzidina (DAB) al 5\%. Los cortes se extendieron en láminas portaobjeto previamente tratadas con gelatina al 1\%, para facilitar su adherencia, se secaron a temperatura ambiente y se montaron con Entellan (Merck). El mismo procedimiento se utilizó para obtener controles negativos pero omitiendo los anticuerpos primarios o secundarios. Además, se hizo un segundo control negativo para la inmunohistoquímica del virus de la rabia en el que se aplicó el protocolo completo a cortes de cerebelo de ratones no infectados (28).

\section{Análisis cualitativo y cuantitativo}

En primer lugar, se verificó la presencia de antígenos virales en las células de Purkinje en los cortes de cerebelo de los animales infectados. Luego se observaron los cortes procesados para inmunohistoquímica de CB para comparar el patrón de marcación de la proteína entre los controles y los infectados. Se enfocó la atención a las características morfológicas y la distribución de las células de Purkinje positivas para CB. El 
análisis cuantitativo se llevó a cabo mediante densitometría óptica (medición del paso de luz a través del tejido sometido a inmunotinción) en los cortes seleccionados. Para ello se realizó primero la captura y digitalización de imágenes en un microscopio Axiophot Zeiss, equipado con una cámara Evolution VF- y software Q capture Pro 6.0. Después se utilizó el programa Image J que cuenta con un sistema para obtener la medida de densidad óptica promedio de acuerdo con una escala de grises en la que se miden los niveles de absorbancia de luz de los cortes (25).

Parallevar a cabo las mediciones se escogieron tres cortes por cada cerebelo (unidad experimental). Se seleccionaron las folias cerebelares II o III, con ayuda del atlas de Paxinos y Franklyn (29), por su facilidad de ubicación y delineación. En cada corte se seleccionaron 20 células de Purkinje de las folias II o III. En ellas se hicieron mediciones por separado de los cuerpos celulares (somas) y de sus correspondientes dendritas (midiendo campos de $0,1 \mathrm{~mm}^{2}$ de la capa molecular). También se midió la densitometría óptica en la folia II completa; por lo tanto, se contó con estas 3 variables para comparar los datos entre los grupos de controles e infectados. En el análisis de los datos se utilizó la prueba no paramétrica de Wilcoxon-Mann-Whitney para comparar los grupos de infectados y sus controles a través del programa InfoStat (25).

\section{RESULTADOS}

\section{Inmunorreactividad a antígenos del virus de la rabia en células de Purkinje}

El antígeno viral se distribuyó ocupando todo el pericarion, el tronco dendrítico principal y parte de las ramas secundarias de las células de Purkinje haciendo resaltar su morfología neuronal (excepto el axón) dentro de la capa molecular. Además, se observaron abundantes inclusiones citoplasmáticas (cuerpos de Negri) tanto en los somas como en las dendritas principales de las células de Purkinje. En los controles no infectados apenas se evidenció un tenue "ruido de fondo" producido por la reacción inespecífica del anticuerpo primario o del cromógeno (DAB) con algunos componentes del tejido nervioso (Figura 1).

\section{Efecto de la infección sobre la expresión de CB en las células de Purkinje}

Las imágenes panorámicas del cerebelo en el microscopio revelaron que sólo las células de Purkinje fueron inmunorreactivas a CB. La distribución de la proteína demarcó la morfología de estas neuronas, destacando su soma y su arborización dendrítica, y acentuó la inmunorreactividad en la capa molecular de la corteza cerebelar (Figura 2). Esta inmunotinción fue homogénea en la mayor parte de las folias en todos los niveles observados, desde los cortes más laterales hasta los del plano medial donde se localizaron las áreas seleccionadas (folias II y III) para hacer las mediciones densitométricas. Al comparar las imágenes de las muestras de los controles con aquellas de los infectados, no se evidenciaron mayores diferencias, aunque en los infectados se notaron más fragmentos de dendritas inmunorreactivas dentro de la capa molecular (Figuras 2B y D).

La evaluación cuantitativa de la expresión de CB mediante densitometría óptica no arrojó diferencia estadísticamente significativa entre la transmitancia de luz obtenida para los cortes de ratones control e infectados en la folia II ( $p>0,999)$, los somas de las células de Purkinje $(\mathrm{p}=0,335)$ y la arborización dendrítica en la capa molecular $(p=0,208)$ (Tabla 1$)$, es decir, no hubo cambio significativo en la inmunotinción de $\mathrm{CB}$, aunque las imágenes (Figuras 2 B y D) mostraron una tendencia al aumento de inmunotinción de CB en las células de Purkinje de los animales infectados. 
Julián Ricardo Naizaque G. y Orlando Torres-Fernández.

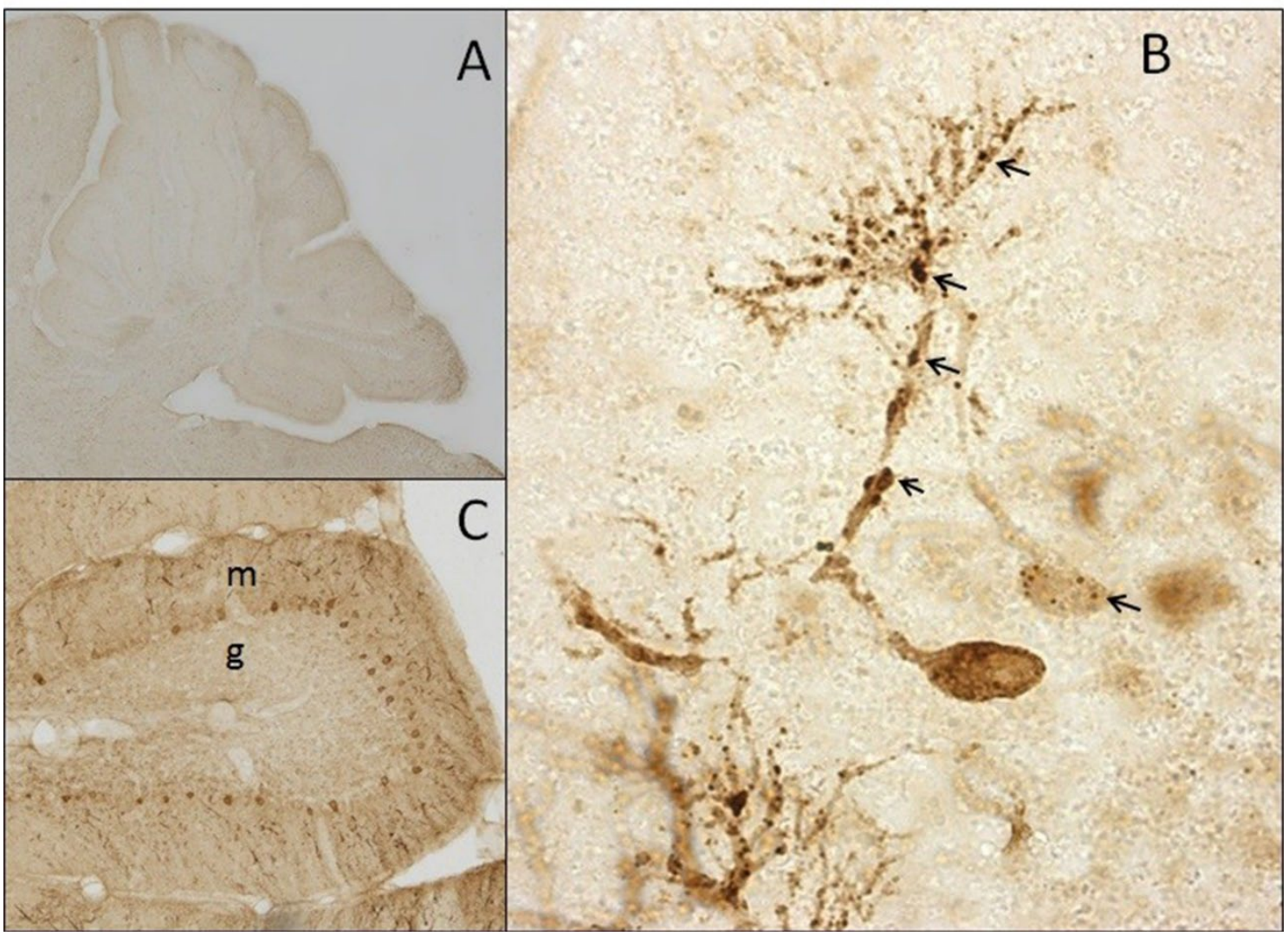

Figura 1. Inmunohistoquímica para rabia en muestras de cerebelo de ratones. A. Imagen panorámica de un corte sagital de cerebelo en un animal control. Apenas se nota un "ruido de fondo" producido por la reacción inespecífica del cromógeno con el tejido nervioso $(2,5 \mathrm{X})$. B. Inmunorreactividad a los antígenos del virus sobre la folia VIII en el cerebelo de un ratón infectado con rabia. La inmunotinción se concentra en los somas de las células de Purkinje y su arborización dendrítica dentro de la capa molecular (2,5X). C. Célula de Purkinje positiva para rabia. La inmunotinción demarca gran parte de la morfología neuronal. Las flechas indican inclusiones intracitoplasmáticas (cuerpos de Negri) (40X). m: capa molecular; g: capa granular. 


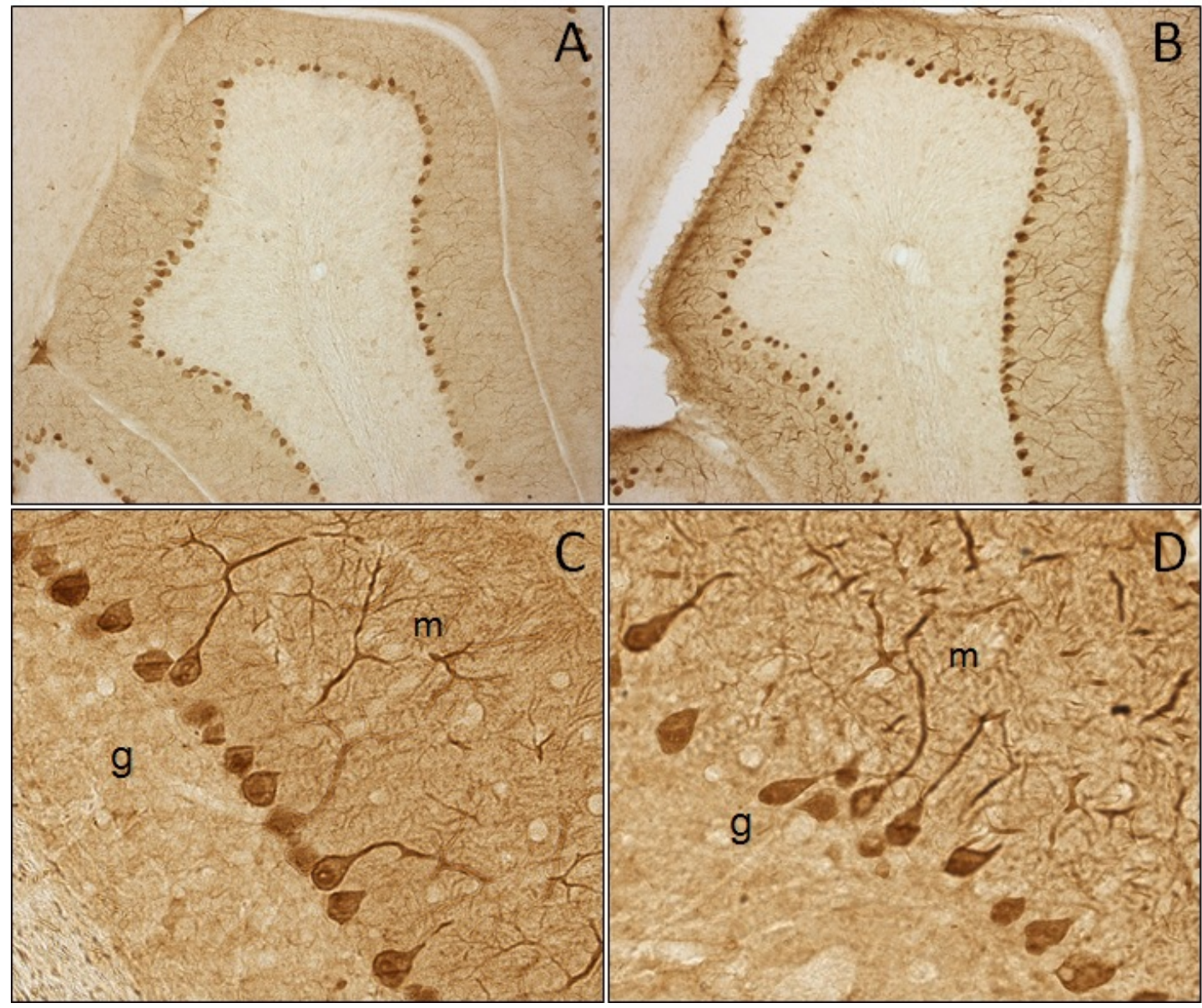

Figura 2. Inmunorreactividad para $\mathrm{CB}$ en muestras de cerebelo de ratones. A. Folia III del cerebelo de un ratón control a nivel del núcleo fastigiado y el cuarto ventrículo (10X). B. Folia III del cerebelo de un ratón infectado con el virus de la rabia a nivel del núcleo fastigiado y el cuarto ventrículo (10X). C. Detalle en mayor aumento de la corteza cerebelar en una muestra control. Es evidente la inmunorreactividad en las células de Purkinje (40X). D. Detalle en mayor aumento de la corteza cerebelar en una muestra de ratón infectado (40X). Nótese una tendencia a la mayor inmunotinción en los infectados. m: capa molecular; g: capa granular. 
Julián Ricardo Naizaque G. y Orlando Torres-Fernández.

Tabla 1. Valores de la densitometría óptica (inmunorreactividad a CB) en la corteza del cerebelo de ratones infectados con rabia y los controles. La medición se realizó en células de Purkinje individuales, en segmentos de la capa molecular, donde la inmunorreactividad está determinada por las dendritas de las células de Purkinje y en campos que abarcaron la folia II completa. Cada dato corresponde al promedio de mediciones tomadas en tres cortes por cada muestra. Los valores se encuentran dentro de una escala que va desde 0 (muy oscuro o $0 \%$ de luz transmitida) hasta 255 (transparente o $100 \%$ de luz transmitida).

\begin{tabular}{|c|c|c|c|c|c|c|}
\hline \multirow[t]{2}{*}{ MUESTRA } & \multicolumn{2}{|c|}{ Células de Purkinje } & \multicolumn{2}{|c|}{ Capa molecular } & \multicolumn{2}{|l|}{ Folias } \\
\hline & Control & Infectado & Control & Infectado & Control & Infectado \\
\hline 1 & 89,33 & 105,34 & 139,95 & 141,24 & 146,80 & 127,85 \\
\hline 2 & 97,11 & 110,26 & 148,15 & 162,59 & 149,72 & 156,93 \\
\hline 3 & 81,30 & 99,70 & 128,85 & 146,84 & 117,46 & 130,44 \\
\hline 4 & 89,58 & 99,88 & 138,07 & 143,76 & 138,62 & 134,13 \\
\hline 5 & 90,99 & 86,23 & 132,09 & 132,17 & 130,55 & 132,88 \\
\hline 6 & 87,43 & 104,66 & 132,17 & 137,26 & 126,99 & 136,53 \\
\hline 7 & 104,44 & 86,95 & 166,14 & 156,59 & 172,96 & 149,61 \\
\hline Promedio & 91,45 & 99,00 & 140,77 & 145,78 & 140,44 & 138,34 \\
\hline \multirow[t]{2}{*}{ DS } & $\pm 7,4$ & $\pm 9,21$ & $\pm 12,9$ & $\pm 10,67$ & $\pm 18,23$ & $\pm 10,77$ \\
\hline & $p=0,2086$ & & $p=0,3351$ & & $p>0,999$ & \\
\hline
\end{tabular}

\section{DISCUSIÓN}

La demarcación de la morfología celular de las neuronas inmunorreactivas y la presencia de cuerpos de Negri abundantes demostraron que el virus infectó masivamente a las células de Purkinje como se había descrito (28). Puesto que el virus se disemina por transporte axonal retrógrado, ingresa primero a los núcleos profundos del cerebelo desde la médula espinal (probablemente haciendo relevo en los núcleos vestibulares y reticulares) y luego es conducido por los axones de las células de Purkinje hasta la corteza cerebelar. Recientemente, se estableció en nuestro modelo animal que el virus llega a los núcleos profundos 64 horas después de ser inoculado por vía intramuscular en las extremidades posteriores y a las 72 horas ya se ha diseminado a las células de Purkinje, mientras que en áreas más distales como el hipocampo la infección fue detectada varias horas después (30).

Del presente trabajo se destaca el hecho de no haber encontrado cambios estadísticamente significativos en la inmunorreactividad a CB de las células de Purkinje por efecto de la infección con el virus CVS de la rabia. Previamente, se había demostrado pérdida de inmunorreactividad a CB en la corteza cerebral $(11,21)$ el estriado (21), el hipocampo (24) y la médula espinal (25) luego de la infección intramuscular con el mismo tipo de virus. También es interesante anotar que el virus de la rabia, a pesar de infectar masivamente a las células de Purkinje, células típicamente gabaérgicas, no provoca en ellas una disminución en la expresión de CB como sí sucede, por ejemplo, con células gabaérgicas de la corteza cerebral y el estriado que son también inmunorreactivas a CB.

Las células de Purkinje, aunque están entre las neuronas más frecuentemente infectadas por el virus de la rabia, parecen tener cierta resistencia a los efectos de la infección experimental con virus CVS en el modelo de ratón. Esto se ha demostrado en estudios en los que se ha inducido apoptosis mediante inoculación intracerebral del virus. Mientras otras neuronas principales que también son infectadas, como 
las células piramidales de la corteza cerebral y el hipocampo, sufren apoptosis, las células de Purkinje son poco susceptibles a ese tipo de muerte neuronal en la patología de la rabia $(31,32)$.

Tampoco es raro que la CB presente diferencias en su inmunorreactividad en diferentes regiones del SNC afectado por una misma patología. Por ejemplo, en la enfermedad de Alzheimer, la $C B$ no parece afectarse en la corteza visual (13) pero disminuye su expresión en neuronas colinérgicas del núcleo basal magnocelular (14). En un estudio se encontró disminución de la concentración de $\mathrm{CB}$ en el núcleo basal con enfermedad de Alzheimer, en la sustancia negra con enfermedad de Parkinson y en el estriado con enfermedad de Huntington, pero no se presentaron cambios en la expresión de $\mathrm{CB}$ en la neocorteza y el cerebelo de las mismas muestras (15). También es conocido el concepto de vulnerabilidad selectiva neuronal en las infecciones virales (33). Así, por ejemplo, en tejido cerebral de pacientes con sida la CB sufre disminución significativa de su inmunorreactividad en la corteza cerebral pero no en los núcleos basales ni en el hipocampo (17).

Otro aspecto que se debe tener en cuenta al evaluar el efecto de la rabia sobre la inmunorreactividad a CB en células de Purkinje de ratón es que estas células también contienen una alta concentración de otra importante proteína reguladora del calcio intracelular, la parvoalbúmina (PV) y las dos moléculas interactúan metabólicamente (34); esto no ocurre en los otros tipos de células $\mathrm{CB}+$ que han sido evaluados. La colocalización de estas dos proteínas simultáneamente en una misma neurona es poco frecuente $(12,34,35)$. Además, el efecto de la rabia sobre la PV ha sido opuesto al observado en CB. La infección genera aumento en la expresión de PV en diferentes partes del sistema nervioso en el modelo de ratón (11, 25), incluyendo las células de Purkinje (36).
La presencia de PV en estas neuronas podría interferir con el efecto de la infección sobre la expresión de CB.

Por último, se podría especular que la CB presente en las células de Purkinje de ratón tiene características bioquímicas diferentes a las de otras neuronas inmunorreactivas a CB. Hay evidencia de que esto puede ocurrir con la $C B$ bajo diferentes condiciones metabólicas $(34,35,37)$; esto podría reflejarse en la respuesta de la proteína a la infección. Para resolver estas inquietudes es necesario emplear otros métodos bioquímicos y moleculares que aporten al conocimiento de la expresión de $\mathrm{CB}$ y otras CaBP en respuesta a la infección con el virus de la rabia.

En un estudio reciente se reportó pérdida de CB en células de Purkinje de bovinos afectados por rabia (38). Esta diferencia con ratones se puede sustentar en que la distribución y tipología de las células inmunorreactivas a las CaBP (incluyendo CB) difieren notablemente entre los artiodáctilos y los órdenes de mamíferos que han sido más estudiados: roedores, carnívoros y primates, los cuales son más afines entre sí (39). Por esta razón, los resultados experimentales con especies de estos últimos taxones son más extrapolables a lo que sucede con el sistema nervioso humano (40).

\section{FINANCIACIÓN}

Este trabajo fue financiado con recursos del Departamento Administrativo de Ciencias, Tecnología e Innovación COLCIENCIAS y el Instituto Nacional de Salud (INS, Colombia). Proyecto Código 210454531601, Contrato 378 de 2011.

\section{CONFLICTO DE INTERESES}

Los autores declaran no tener ningún conflicto de interés relacionado con este artículo. 
Julián Ricardo Naizaque G. y Orlando Torres-Fernández.

\section{REFERENCIAS}

1. World Health Organization. WHO expert consultation on rabies. En: Technical Report Series No. 982. Geneva: WHO Press 2013; p. 1-139.

2. Fooks AR, Banyard AC, Horton DL, Johnson N, McElhinney LM, Jackson AC. Current status of rabies and prospects for elimination. Lancet $2014 ; 384: 1389-99$.

3. Vigilato M, Cosivi O, Clavijo A, Silva H. Rabies update for Latin America and the Caribbean. Emerg Infect Dis 2013; 19:678-9.

4. Cediel N, de la Hoz F, Villamil LC, Romero J, Díaz A. Epidemiología de la rabia canina en Colombia. Rev Salud Pública 2010; 12: 368-79.

5. Jackson AC. Rabies. Neurol Clin 2008; 26:717-26.

6. Hemachudha T, Ugolini G, Wacharapluesadee S, Sungkarat W, Shuangshoti S, Laothamatas J. Human rabies: neuropathogenesis, diagnosis, and management. Lancet Neurol 2013; 12:498-513.

7. Iwasaki Y, Tobita M. Pathology. En: Jackson AC, Wunner WH, editores. Rabies. San Diego: Academic Press 2002. p. 283-306.

8. Jackson AC, Randle E, Lawrance G, Rossiter JP. Neuronal apoptosis does not play an important role in human rabies encephalitis. J Neurovirol 2008; 14:368-75.

9. Suja MS, Mahadevan A, Madhusudana SN, Shankar SK. Role of apoptosis in rabies viral encephalitis: A comparative study in mice, canine, and human brain with a review of literature. Patholog Res Int $2011 ; 2011: 374286$. doi: $10.4061 / 2011 / 374286$.

10. Fu ZF, Jackson AC. Neuronal dysfunction and death in rabies virus infection. J Neurovirol 2005; 11:101-6.

11. Torres-Fernández O, Yepes G, Gómez J, Pimienta H. Efecto de la infección por el virus de la rabia sobre la expresión de parvoalbúmina, calbindina y calretinina en la corteza cerebral de ratones. Biomédica 2004; 24:63-78.

12. Andressen C, Blumcke I, Celio M. Calcium-binding proteins: selective markers of nerve cells. Cell Tissue Res 1993; 271:181-208.

13. Leuba G, Kraftsik R, Saini K. Quantitative distribution of parvalbumin, calretinin, and calbindin D-28k immunoreactive neurons in the visual cortex of normal and Alzheimer cases. Exp Neurol 1998; 152:278-91.

14. Ahmadian SS, Rezvanian A, Peterson M, Weintraub S, Bigio EH, Mesulam MM, Geula C. Loss of calbindin-D28K is associated with the full range of tangle pathology within basal forebrain cholinergic neurons in Alzheimer's disease. Neurobiol aging 2015; 36:3163-70.

15. Iacopino AM, Christakos S. Specific reduction of calcium-binding protein (28-kilodalton calbindin-D) gene expression in aging and neurodegenerative diseases. Proc Natl Acad Sci U S A 1990; 87:4078-82.

16. Beasley C, Zhang Z, Patten I, Reynolds G. Selective deficits in prefrontal cortical GABAergic neurons in schizophrenia defined by the presence of calcium binding proteins. Biol Psychiatry.2002; 52:70815.

17. Masliah E, Ge N, Achim CL, Wiley CA. Differential vulnerability of calbindin-immunoreactive neurons in HIV encephalitis. J. Neuropathol Exp Neurol 1995; 54:350-7.

18. Schmidt $\mathrm{H}$. Three functional facets of calbindin D-28k. Front Mol Neurosci 2012; 5:25. doi: 10.3389/ fnmol.2012.00025.

19. Schwaller B. The continuing disappearance of "pure" Ca2+ buffers. Cell Mol Life Sci 2009; 66:275-300.

20. Flace $P$, Lorusso L, Laiso G, Rizzi A, Cagiano R, Nico B, et al. Calbindin-D28K immunoreactivity in the human cerebellar cortex. Anat Rec 2014; 297:1306-15. 
21. Torres-Fernández O, Yepes GE, Gómez JE, Pimienta HJ. Calbindin distribution in cortical and subcortical brain structures of normal and rabies-infected mice. Int J Neurosci 2005; 115:1375-82.

22. Ladogana A, Bouzamondo E, Pocchiari M, Tsiang H. Modification of tritiated $y$-amino-n-butyric acid transport in rabies virus-infected primary cortical cultures. J Gen Virol 1994; 75:623-7.

23. Rengifo AC, Torres-Fernández O. Disminución del número de neuronas que expresan GABA en la corteza cerebral de ratones infectados con rabia. Biomédica 2007; 27:548-58.

24. Lamprea N, Torres-Fernández O. Evaluación inmunohistoquímica de la expresión de calbindina en el cerebro de ratones en diferentes tiempos después de la inoculación con el virus de la rabia. Colomb Med 2008; 39 (Supl.3): 7-13.

25. Monroy-Gómez J, Torres-Fernández O. Distribución de calbindina y parvoalbúmina y efecto del virus de la rabia sobre su expresión en la médula espinal de ratones. Biomédica 2013; 33:564-73.

26. Vigot R, Kado RT, Batini C. Increased calbindin-D28K immunoreactivity in rat cerebellar Purkinje cell with excitatory amino acids agonists is not dependent on protein synthesis. Arch Ital Biol 2004; 142:69-75.

27. Koprowski H. The mouse inoculation test. En: Meslin FX, Kaplan MM, Koprowski H, editores. Laboratory Techniques in Rabies. Geneva: World Health Organization, 4th ed; 1996. p. 80-7.

28. Lamprea NP, Ortega LM, Santamaría G, Sarmiento L, Torres-Fernández O. Elaboración y evaluación de un antisuero para la detección inmunohistoquímica del virus de la rabia en tejido cerebral fijado en aldehídos. Biomédica 2010; 30:146-51.

29. Paxinos G, Franklyn, KB. The mouse brain in stereotaxic coordinates. San Diego: Academic Press; 2001.

30. Torres-Fernández O, Santamaría G, Monroy-Gómez J. Dinámica neuroanatómica de infección celular en la ruta de dispersión del virus de la rabia en ratones inoculados por vía intramuscular. Biomédica 2015; 35 (Supl. 3):113-4.

31. Jackson AC, Rossiter JP. Apoptosis plays an important role in experimental rabies virus infection. J Virol 1997; 71:5603-07.

32. Jackson AC, Park H. Apoptotic cell death in experimental rabies in suckling mice. Acta Neuropathol 1998; 95:159-64.

33. Johnson R. Selective vulnerability of neural cells to viral infection. Brain 1980; 103:447-72.

34. Schwaller B, Meyer M, Schiffmann S. 'New' functions for 'old' proteins: the role of the calcium-binding proteins calbindin D-28k, calretinin and parvalbumin, in cerebellar physiology. Studies with knockout mice. Cerebellum 2002; 1:241-58

35. Krebs J, Heizmann CW. Calcium-binding proteins and EF-hand principle. En: Krebs J, Michalak M, editores. Calcium: A matter of life or death. Amsterdam: Elsevier B.V.; 2007. p. 51-93.

36. Rengifo AC, Torres-Fernández $\mathrm{O}$. Cambios en los sistemas de neurotransmisión excitador e inhibitorio en el cerebelo de ratones infectados con virus de la rabia. Biomédica 2013; 33 (Supl. 2):80-81.

37. Winsky L, Kuźnicki J. Antibody recognition of calcium-binding proteins depends on their calciumbinding status. J Neurochem 1996; 66:764-71.

38. Verdes JM, de Sant'Ana FJ, Sabalsagaray MJ, Okada K, Calliari A, Moraña JA, de Barros CS. Calbindin D28k distribution in neurons and reactive gliosis in cerebellar cortex of natural rabies virus-infected cattle. J Vet Diagn Invest 2016. May 6. doi: 10.1177/1040638716644485.

39. Hof P, Glezer I, Condé F, Flagg R, Rubin M, Nimchinsky E, Vogt DM. Cellular distribution of the calciumbinding proteins parvalbumin, calbindin and calretinin in the neocortex of mammals: phylogenetic and developmental patterns. J Chem Neuroanat 1999; 16:77-116

40. Rockel A, Hiorns R, Powell T. The basic uniformity in structure of the neocortex. Brain 1980; 103: 221-44. 